\title{
Influence of different surface treatment on water penetration resistance of concrete
}

\author{
Li Tianlun $^{1, *}$, Wu Yonggen ${ }^{1}$ \\ ${ }^{1}$ Aeronautical Engineering College, Air Force Engineering University, Xi’an, Shaanxi, China
}

\begin{abstract}
Concrete is easily affected by all kinds of erosive substances during its use. Surface treatment is a simple method to improve the surface compactness and water permeability resistance of concrete. In this paper, silicate infiltration agent, nano-SiO2 and ethyl silicate are selected as concrete surface treatment material. The results of water permeability test showed that all the three treatments can effectively improve the water resistance. Silicate infiltration agent and nano-SiO2 were the most effective, which greatly reduced the penetration depth of water from $66 \mathrm{~mm}$ to $34 \mathrm{~mm}$ and $32 \mathrm{~mm}$, while ethyl silicate was reduced to $50 \mathrm{~mm}$. Through the water permeability test curve, we can see that the water entered the concrete under a certain pressure, and the result showed the shape of high, middle and low edge.
\end{abstract}

\section{Introduction}

Various corrosive substances in the external environment enter concrete along pores and cracks, causing loss of effective components or structural cracking through chemical reaction or physical expansion, and ultimately affecting the strength and bearing capacity of concrete. Among the many invading materials, water is the most important to the invasion and permeation of concrete. Water is an important factor in the formation strength of early concrete, but when concrete structures enter service, water infiltration will become a key factor leading to deterioration of concrete. The influence of water on concrete includes at least the following three types: first, after water enters concrete, it freezes in the freezing season, leading to concrete structure cracking. Secondly, gases in the environment can dissolve in concrete water to form acids. For example, by dissolving $\mathrm{CO} 2$ and $\mathrm{SO} 2$, pure water can be converted into acid water, which can react quickly with cement hydration products, not only causing the loss of effective components in concrete, but even causing concrete expansion and porosity [1].The third is that in corrosive erosion, water basically acts as a carrier to transport dissolved harmful ions to the porous system of concrete. For example, the invasion of chlorine ions will reduce $\mathrm{pH}$ value, destroy the passivation film of steel reinforcement, lead to corrosion of steel reinforcement, and reduce its bearing capacity. Meanwhile, chlorine ions will also accelerate freezing damage of concrete [2].In addition to corrosive attack, water is also a key factor in other physical and chemical damages. For example, in alkali aggregate reactions, whether alkali silicate or alkali carbonate reactions, structural damage is caused by water absorption expansion of the reaction products. Therefore, it can be seen that the permeability of water is an important aspect of concrete permeability.

The improvement of concrete by surface treatment has been studied deeply at home and abroad[3, 4].Through experiments, Zhao et al. believed that the film-forming coating surface treatment materials were superior to silane materials in reducing water infiltration, chloride ion invasion and gas penetration[5], but the film-forming coating was easily affected by the external environment and would gradually fall off under the dry-wet cold and hot cycle[6].Aguiar compared the effects of acrylic resin, siloxane and epoxy resin treatment on the carbonation depth of concrete, and the research showed that epoxy resin had the strongest carbonation resistance and siloxane had the weakest carbonation resistance[7]. Franzoni compared ethyl silicate, sodium silicate and nano-SiO2 solution. The test showed that ethyl silicate had the best effect in reducing water absorption, but it was also the curing agent with the largest consumption[8]. In this paper, the influence of three surface treatments on concrete permeability is evaluated from water permeability resistance.

\section{Materials and methods}

\subsection{Materials}

In this test, the cement used is PO 42.5 , fineness modulus of river sand is 2.75 , The coarse aggregate is limestone and the compact density is $1.637 \mathrm{~kg} / \mathrm{m}^{3}$. 
Table1. Mix Ratio and flexural strength of concrete

\begin{tabular}{cccccc}
\hline & \multicolumn{2}{c}{$\operatorname{mix}\left(\mathrm{kg} / \mathrm{m}^{3}\right)$} & & $\mathrm{Vb} / \mathrm{s}$ & $28 \mathrm{~d}$ flexural strength \\
Cement & water & sand & Coarse aggreate & & $\mathrm{MPa}$ \\
320 & 140.8 & 622 & 1391 & 22 & 5.2 \\
\hline
\end{tabular}

The silicate infiltration agent is the product of Hunan Fenghang New Materials Co., LTD.,labeled as L. And the nano-SiO2 is from Shanghai Zhichuang Fine Chemical Co., LTD., labeled as S. Ethyl silicate surrface treatment uses 75 wt.\% ethyl silicate and 25 wt.\% anhydrous ethanol, labeled as T. Concrete which no surface treatment is labeled as $\mathrm{N}$.

\subsection{Test methods}

The round-shaped sample is made and cured in

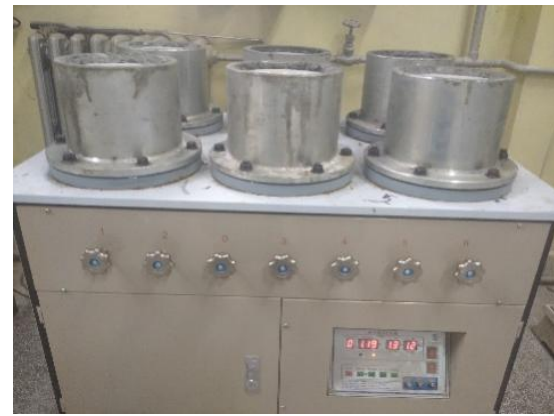

Figure 1. Concrete anti-permeability meter

\section{Results \& Discussion}

\subsection{Analysis of water seepage curve}

The distance between the measuring point and the centerline of the sample section on the cleavage section of the sample is set as 1-5 respectively from near to far. The penetration depth of each sample at the same distance was averaged, and the average value of six samples in each group was taken to draw the penetration curve, as shown in Figure 3. From the curve, it can be seen that water permeates in the concrete, showing a high middle, and the untreated samples are more obvious. accordance with the specifications ${ }^{[9]}$, and it is taken out and dried after 28 days of curing. It is dried to the bottom surface (bearing water pressure surface) for surface brushing. After the brushing, it is cured for 10 days in an indoor environment ( $\left.\mathrm{RH}=50 \pm 10 \%, \mathrm{~T}=20 \pm 2^{\circ} \mathrm{C}\right)$ for sealing and molding. After the completion of sealing, it is installed on the anti-permeability meter as shown in Figure 1. Water pressure is increased to $1.2 \pm 0.05 \mathrm{mpa}$ and kept constant in $5 \mathrm{~min}$. After $24 \mathrm{~h}$, it is taken out and split to measure the penetration depth, as shown in Figure 2. The average value of 6 samples was taken as the final test result.

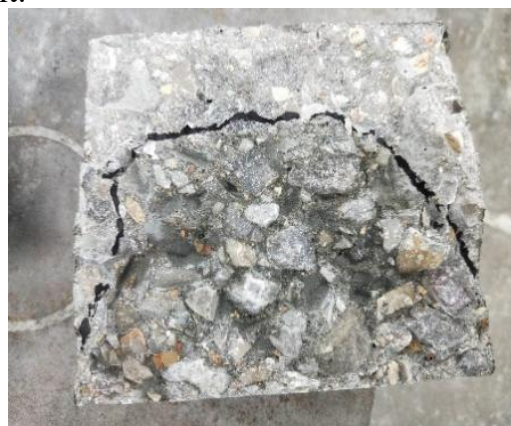

Figure 2. Depth of water penetration

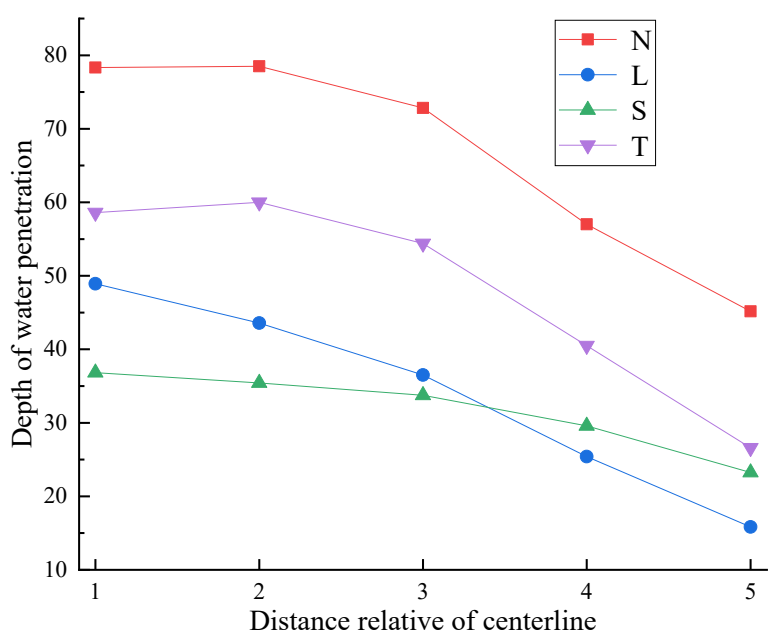

Figure 3. Depenetation curve

\subsection{Water permeability resistance of concrete after different surface curing treatment}

Figure 4. shows the penetration depth of different surface treatments. Among the three surface treatments, the nano$\mathrm{SiO}_{2}$ has the best effect reducing the penetration depth from $66 \mathrm{~mm}$ to $32 \mathrm{~mm}$, and the penetration depth reduction rate compared with no treatment is $52.1 \%$. The second is silicate infiltration agent, depth of water penetration after treatment is $34 \mathrm{~mm}$ with reduction rate compared with no treatment is $48.7 \%$, while the reduction rate of ethyl silicate treatment is only $27.6 \%$. The surface treatment 
mainly enhances the resistance of water permeability in concrete in two ways, one is to form a thin film on the concrete surface to prevent water from entering, the other is to block the pores of the concrete surface to increase the resistance of water entering.

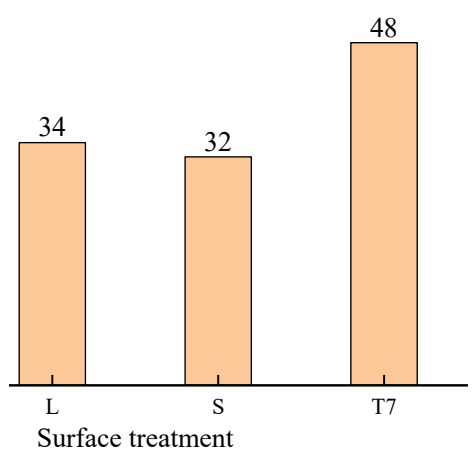

Figure 4. Depth of water penetration of different surface treatment

\section{Mechanism analysis}

For water permeability resistance of concrete, because it is water penetration under a certain pressure $(1.2 \mathrm{MPa})$, so the connectivity rate and the degree of tortuosity of the pores are more important. In addition to filling the pores, silica permeable agent also forms $\mathrm{Si}-\mathrm{O}-\mathrm{Si}$ network structure on the concrete surface, and forms a thin film under the dispersion of alkali metals and other salts ${ }^{[10]}$. The presence of the thin film further enhances the concrete's resistance to water pressure, as shown in Figure 5 the test surface after the test of the specimen cured by silica permeable agent. Nano- $\mathrm{SiO}_{2}$ itself has a filling function, entering into the interior of the pores to reduce the connectivity of the pores, and nano- $\mathrm{SiO}_{2}$ particles also converge on the surface of the concrete to integrate the film, as shown in Figure 6. It is worth noting that the bottom surface of the concrete water permeability resistant specimen is used as the permeability surface. In the process of concrete vibration compaction, the cement mortar moves upward, and there is less cement mortar at the bottom, which increases the possibility of the transition zone around the aggregate and the occurrence of micro-cracks, which is conducive to the infiltration of large-size nano- $\mathrm{SiO}_{2}$. At the same time, due to the small amount of cement slurry on the bottom surface and the leakage of some sand and gravel caused by steel wire ball brushing, the ethyl silicate mainly relies on the reaction with hydration product hydroxycalcite to form gel. When the content of cement slurry is small or the porosity is large, the treatment effect of ethyl silicate will decrease.

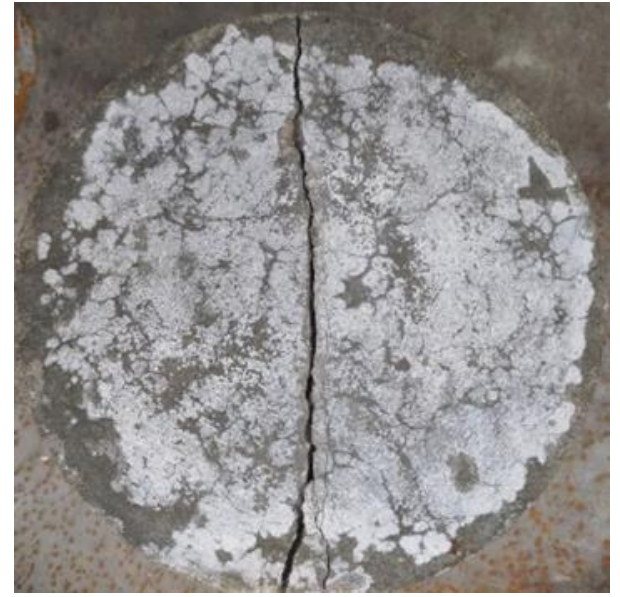

Figure 5. Silicone curing treatment surface

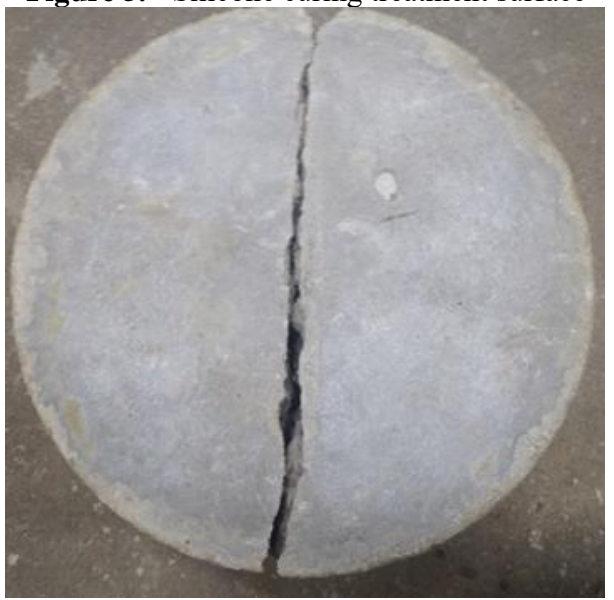

Figure 6. Nano- $\mathrm{SiO}_{2}$ curing treatment surface

\section{Conclusions}

1. The surface treatment can effectively improve water permeability of concrete.

2. In terms of reducing penetration, the nano- $\mathrm{SiO}_{2}$ has the best effect, depth reduction rate compared with no treatment is $52.1 \%$, second is silicate infiltration agent with reduction rate $48.7 \%$. Ethyl silicate reduces the penetration depth from $66 \mathrm{~mm}$ of no treatment to $48 \mathrm{~mm}$.

\section{References}

1. ACI. 515.2R-13 Guide to Selecting Protective Treatments for Concrete[R]. Farming Hills: ACI,2013.

2. Zhang P, Shang H, Hou D, et al. The Effect of Water Repellent Surface Impregnation on Durability of Cement-Based Materials[J]. Advances in Materials Science and Engineering, 2017, 2017:1-9.

3. Almusallam A A, Khan F M, Dulaijan S U, et al. Effectiveness of surface coatings in improving concrete durability[J]. Cement and Concrete Composites, 2003, 25(4):473-481.

4. Diamanti M V, Brenna A, Bolzoni F, et al. Effect of polymer modified cementitious coatings on water and chloride permeability in concrete $[\mathrm{J}]$. Construction 
and Building Materials, 2013, 49:720-728.

5. Zhao Y X, Du P F and Jin W L. Evaluation of the performance of surface treatments on concrete durability[J]. Journal of Zhejiang University: Science A, 2010, 11(5):349-355.

6. Yang P. Study on the effection of surface treatment for reinforced concrete structure in marine environment [D]. Qingdao: Qingdao Technological University,2012.

7. Guo T, Weng X. Evaluation of the freeze-thaw durability of surface-treated airport pavement concrete under adverse conditions[J]. Construction and Building Materials, 2019, 206:519-530.

8. Franzoni E, Pigino B and Pistolesi C. Ethyl silicate for surface protection of concrete: Performance in comparison with other inorganic surface treatments[J]. Cement and Concrete Composites, 2013, 44:69-76.

9. Leng F , Rong $\mathrm{J}$, Wei D , et al. Introduction of Revised Standard for Test Methods of Long-term Performance and Durability of Ordinary Concrete GB/T 50082-2009[J]. Construction Technology, 2010.

10. Guo D S.Preparation and Properties of Hydrosilicate Coatings [J].Chemical Building Materials, 1988, (04):19-21. 